(2) OPEN ACCESS

${ }^{1}$ Neurology, Cork University Hospital Group, Cork, Ireland ${ }^{2}$ Microbiology, Cork University Hospital Group, Cork, Ireland ${ }^{3}$ Radiology, Cork University Hospital Group, Cork, Ireland

\section{Correspondence to}

Dr Geoffrey Ronan, Neurology, Cork University Hospital Group, 1 Hollymount House, Lee Road, Cork, Ireland, T23KPK3; 111314731@umail.ucc.ie

Accepted 25 May 2020

Check for updates

(c) Author(s) (or their employer(s)) 2020. Re-use permitted under CC BY-NC. No commercial re-use. See rights and permissions. Published by BMJ.

To cite: Ronan G, Barry R, Fanning $\mathrm{N}$, et al. Pract Neurol 2020;20:502-503.

\title{
Non-traumatic CSF rhinorrhoea
}

\author{
Geoffrey Ronan, ${ }^{1}$ Rachel Barry, ${ }^{2}$ Noel Fanning, ${ }^{3}$ Áine Merwick ${ }^{1}$
}

A 53-year-old woman presented with acute onset of bifrontal headache with fever and vomiting, and a 6-week history of unilateral, left-sided, clear, salty rhinorrhoea. She worked as a veterinary pathologist. On examination, her neck movements were painful, but there were no localising neurological signs. She was obese with a body mass index of $36.5 \mathrm{~kg} / \mathrm{m}^{2}$ (height $162 \mathrm{~cm}$, weight $96 \mathrm{~kg}$ ). Cerebrospinal fluid (CSF) examination identified a pleocytosis with a white cell count of 2910/ $\mathrm{L}$ ( $\leq 5)$, 91\% polymorphs and 9\% lymphocytes. The level of CSF glucose was low at $3.9 \mathrm{mmol} / \mathrm{L}$, with a $\mathrm{CSF} /$ serum ratio of 0.66. CSF protein was markedly raised at $3.38 \mathrm{~g} / \mathrm{L}(0.15-0.45)$. We made a presumptive diagnosis of bacterial meningitis and started antimicrobial cover as per local guidelines. This did not include corticosteroids or anti-tuberculous therapy.

Given her occupation, and recent travel to Yosemite National Park, California, we excluded an extensive list of pathogens. CSF PCR was negative for Neisseria meningitidis, Streptococcus pneumoniae, Escherichia coli, Streptococcus agalactiae, Haemophilus influenzae, Listeria monocytogenes, cytomegalovirus, enterovirus, herpes simplex virus type 1 (HSV-1) and type 2 (HSV-2), human herpesvirus 6, varicella zoster virus, human parechovirus and Cryptococcus neoformans. There was no serological evidence of hantavirus, Rickettsia, Treponema pallidum, Borrelia burgdorferi, Leptospira, Histoplasma, Coccidioides or Brucella. Beta-(1,3)-dglucan and cryptococcal antigens were negative in both serum and CSF samples. Serum Aspergillus antigen (galactomannan) was also negative.

Chest X-ray identified a coexisting right basal pneumonia, confirmed on CTscan of thorax, which also showed evidence of prior granulomatous disease. She was known to have a reactive Mantoux, from occupational screening many decades previously. QuantiFERON-TB Gold was positive, but extended mycobacterial cultures on CSF and bronchoalveolar lavage were negative. Investigative work-up for granulomatous disease showed serum ACE of 38 IU (8-65), adjusted serum calcium of $2.36 \mathrm{mmol} / \mathrm{L}$ (2.25-2.59), erythrocyte sedimentation rate of $11 \mathrm{~mm} /$ hour (1-20), negative anti-neutrophil cytoplasmic antibody and normal serum immunoglobulins. Bronchoscopy was macroscopically normal. Bacterial culture and PCR on bronchoalveolar lavage fluid were negative.

A follow-up CTscan of thorax 3 months later showed resolution of consolidation and stable granulomatous disease, with calcified lymph nodes. MR scan of brain highlighted meningeal enhancement consistent with recent meningitis and left mucosal sinus enhancement, probably from recurrent sinusitis. High-resolution non-contrast CT scan of the paranasal sinuses, searching for signs of CSF leak, was inconclusive.

She improved to a level at which discharge was appropriate and we arranged outpatient otolaryngological follow-up. Before discharge, we sent a nasal discharge sample for beta-2 transferrin concentration.

Unfortunately, she was readmitted 1 week later with pneumonitis. Her beta- 2 transferrin in nasal discharge was elevated at $14.10 \mathrm{mg} / \mathrm{L}$ (negative $<1.30 \mathrm{mg} / \mathrm{L}$, possible $1.31-8.88 \mathrm{mg} / \mathrm{L}$, positive $>8.89 \mathrm{mg} /$ L), strongly suggesting that it was CSF. This prompted further investigation for a CSF leak with intrathecal contrastenhanced CT/MR cisternography, which identified a CSF fistula in the planum sphenoidale, the roof of the left sphenoid sinus (figures 1 and 2).

In the absence of prior trauma, we diagnosed spontaneous CSF rhinorrhoea. We gave pneumococcal vaccine and discharged her home on prophylactic amoxicillin until she could have definitive surgical management.

Spontaneous CSF rhinorrhoea is rare, poorly understood and variable. Obesity is a known risk factor. It is probably linked to the development of intracranial hypertension, with resulting bone 


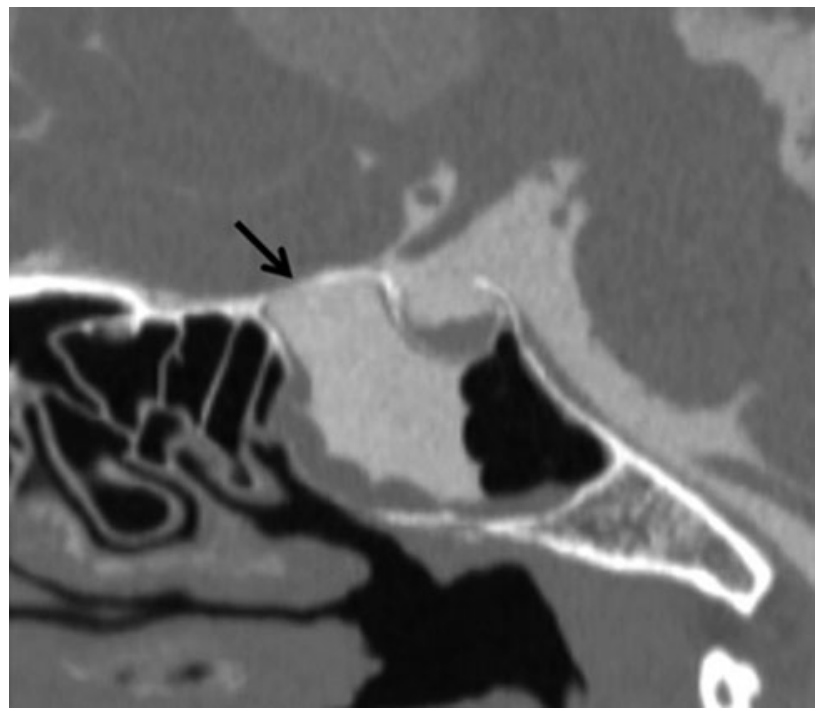

Figure 1 CSF rhinorrhoea. Sagittal CT cisternogram obtained after injection of $8 \mathrm{~mL}$ of intrathecal iohexol showing contrast leakage through a defect in the planum sphenoidale (arrow) with contrast extending from the cranial subarachnoid space and accumulating in the left sphenoid sinus.

CSF, cerebrospinal fluid.

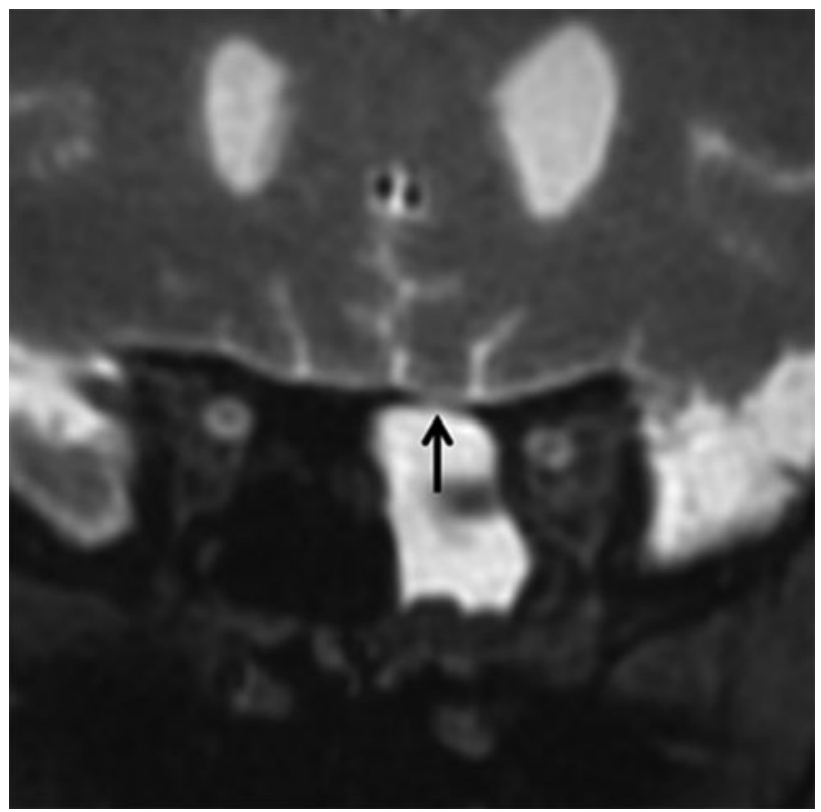

Figure 2 CSF rhinorrhoea. Coronal T1-weighted MR cisternogram obtained after $0.2 \mathrm{~mL}$ of intrathecal gadobutrol injection $(1.0 \mathrm{mmol} / \mathrm{mL}$ ) showing contrast leakage (arrow) extending from the cranial subarachnoid space into the sphenoid from a defect in the left side of the planum sphenoidale - roof of the sphenoid sinus. CSF, cerebrospinal fluid. remodelling and thinning. ${ }^{1}$ Coughing, sneezing and any other causes of fluctuating intracranial pressure may affect its progression.

In this case, the combination of raised body mass index and recurrent sinusitis with coughing and sneezing was probably important in forming the fistula, in turn leading to bacterial meningitis and aspiration pneumonitis.

This diagnosis requires a thorough investigation and a high index of suspicion. CT and MR cisternography are effective for evaluating and localising suspected CSF fistulae along the skull base and for guiding surgical repair. ${ }^{2}$

She underwent an urgent endoscopic CSF leak repair under the care of otolaryngology. Eight weeks postoperatively, she had mild fatigue and headache but was otherwise well, and has had no further rhinorrhoea or episodes of meningitis. At 6-month follow-up, she had recovered fully, had returned to regular exercise and is planning her return to work.

Contributors ÁM was the leading consultant treating the patient and reviewing the manuscript. GR gathered information of the patient and wrote the case report. NF provided neuroradiological guidance and investigation throughout her treatment along with a review of this aspect of the case report. RB provided microbiological guidance and advice on treatment cover along with a review of the article.

Funding None.

Competing interests None declared.

Patient consent for publication Obtained.

Data sharing statement Not applicable.

Provenance and peer review Not commissioned. Externally peer reviewed by Tyagi Alok, Glasgow, UK, and Paul Smith, Bristol, UK.

Open access This is an open access article distributed in accordance with the Creative Commons Attribution Non Commercial (CC BY-NC 4.0) license, which permits others to distribute, remix, adapt, build upon this work non-commercially, and license their derivative works on different terms, provided the original work is properly cited, appropriate credit is given, any changes made indicated, and the use is non-commercial. See: http://creativecommons.org/licenses/by-nc/4.0/.

\section{REFERENCES}

1 Badia L, Loughran S, Lund V. Primary spontaneous cerebrospinal fluid rhinorrhea and obesity. Am J Rhinol 2001;15: 117-19.

2 Stone JA, Castillo M, Neelon B, et al. Evaluation of CSF leaks: high-resolution CT compared with contrast-enhanced CT and radionuclide cisternography. AJNR Am J Neuroradiol 1999;20:706-12. 